\title{
Rapeseed is an efficient energy crop which can still improve
}

Francis FLENET ${ }^{1}$

Antoine POUPART ${ }^{2}$

Dominique WAGNER ${ }^{1}$

${ }^{1}$ CETIOM - Centre de Grignon,

Av. Lucien Brétignières,

78850 Thiverval-Grignon

2 INVIVO - 83, avenue de la Grande Armée, 75782 Paris cedex 16

\begin{abstract}
The ability of biofuels to contribute efficiently to the replacement of fossil energy and to the reduction of greenhouse gas emissions has been a matter of debate. Hence, there is a need to assess accurately the energy balance of biofuels and their ability to reduce greenhouse gas emissions, in order to evaluate and to improve the benefit for society. In rapeseed, the energy ratio (energy produced per unit of non-renewable energy input) is well above 2 whatever the method of calculation. In order to investigate the variability of energy ratios and to identify ways of improvement, a study was conducted in France in 2005 and 2006. The method of mass allocation of input energy was used for calculations, instead of the substitution method, because with this method the results do not depend on the utilization of co-products. Hence, this method is better adapted to follow improvements. A great variability in the energy ratio was observed in 2005 and 2006. Seed yields and energy cost of fertilizer $N$ explained most of this variability. Hence, improvements should focus on increasing yield with little increase in energy cost, and on decreasing wasting of $\mathrm{N}$ fertilizer. However the farmer incomes, and the net production of energy per hectare, must also be a matter of concern. The inventories of greenhouse gas emissions of biofuels are still uncertain because of the great variability of soil emissions, due to environmental and management factors. Hence, in order to assess the effect of rapeseed on greenhouse gas emissions, methods based on process-oriented models accounting for these factors must be used. Such models give promising results, but further testing is still needed.
\end{abstract}

Key words: biofuels, rapeseed, energy balance, greenhouse gas emissions

biofuels, and to relate the results to crop management. Hence, ways of improvement have been found. For greenhouse gas, accurate methods of evaluation are still under investigation. This article deals with both energy and greenhouse gas impacts. Local impacts like water quality and biodiversity are also worth studying. Such works will be carried on and the results will be presented in another article.

\section{The energy content of rapeseed methyl ester is twice as great as the energy required to produce this biofuel and the co-products}

In France, the mean seed yield of rapeseed is highly variable between years (Source: SCEES). However, there has been a clear tendency of increased yields with year with no evidence of a plateau. Hence, assuming a linear increase of yields with years from 1957 to 2006 , the calculated value for 2007 was $3.5 \mathrm{t} \mathrm{ha}^{-1}$ ( $9 \%$ humidity, $2 \%$ impurity). With such a yield, one hectare of land provided oil to produce $1.38 \mathrm{tha}^{-1}$ of rapeseed methyl ester (RME) and significant amounts of co-products (table 1). RME is used as a biofuel by incorporating it into diesel. The total requirement for crop management of rapeseed and for processing the seeds and the oil to produce RME was $24.69 .10^{9} \mathrm{~J} \mathrm{ha}^{-1}$ of non-renewable energy plus $0.33 .10^{9} \mathrm{~J} \mathrm{ha}^{-1}$ of renewable energy (table 2). This included the energy cost to produce the inputs (fertilizer, pesticides... methanol). The energy content of $1.38 \mathrm{tha}^{-1}$ of RME was twice as great as the total energy required to produce this biofuel and the co-products. Hence, the ability of RME to significantly contribute to the replacement of fossil energy is unquestionable. However, for an accurate evaluation of the balance between the energy input and the biofuel output, the energy required to produce the co-products must be deducted from the total input. According to the Life Cycle Assessment method [4], the energy input attributed to the co-products should be the energy required to produce the products which they replace. This way of allocating the energy input between the product and the co-products is called substitution. If such an allocation is not possible, for instance if the co-products do not replace any product, it must be done on a physical basis (mass, energy...). With this latter method of allocation, the energy cost per physical unit of product and co-products (gram, joule...) is assumed to be the same, whatever their utilizations. If the allocation on a physical basis is not possible, other relationships between product and

Table 1. Outputs from 1 hectare of rapeseed.

\begin{tabular}{|lc|}
\hline & Yield $\left(\mathbf{t ~ h a}^{\mathbf{- 1}}\right)$ \\
\hline Seed (0\% water content) & 3.19 \\
RME & 1.38 \\
Cake (0\% water content) & 1.69 \\
Glycerol & 0.14 \\
Acid oil and soap & 0.09 \\
\hline
\end{tabular}


Table 2. Energy balance of rapeseed $\left(10^{9} / h^{-1}\right)$.

\begin{tabular}{|c|c|c|c|c|c|}
\hline \multicolumn{2}{|c|}{ Total energy input } & \multicolumn{3}{|c|}{$\begin{array}{c}\text { Non-renewable energy input } \\
\text { assigned to RME }\end{array}$} & \multirow{2}{*}{$\begin{array}{c}\text { Energy } \\
\text { content } \\
\text { of RME }\end{array}$} \\
\hline Renewable & Non-renewable & $\begin{array}{c}\text { Allocation } \\
\text { by mass }\end{array}$ & $\begin{array}{l}\text { Allocation by } \\
\text { energy content }\end{array}$ & $\begin{array}{l}\text { Substitution } \\
\text { method }\end{array}$ & \\
\hline 0.33 & 24.69 & 14.03 & 17.95 & 10.21 & 51.60 \\
\hline
\end{tabular}

Source: Sofiproteol - Ecobilan (2007).

Table 3. Energy ratio of RME.

\begin{tabular}{|lcc|}
\hline Allocation by mass & Allocation by energy content & Substitution method \\
\hline 3.68 & 2.87 & 5.06 \\
\hline
\end{tabular}

Source: Sofiproteol - Ecobilan (2007).

co-products must be found. For instance, the economical value may be used. In the case of $\mathrm{RME}$, the method to allocate the energy input had a great effect on the energy balance. The non-renewable energy input assigned to RME ranged from 41 to $73 \%$ of the total nonrenewable input, depending on the method of allocation. Hence, the energy ratio of RME, which is the ratio between energy content of RME and the non-renewable energy assigned to $\mathrm{RME}$, ranged from 2.87 to 5.06 (table 3 ). As expected, the allocation of energy input to RME was greater on an energy than on a mass basis, because the energy content of the oil used for the biofuel is greater than the energy content of the two main co-products (cake and glycerol). The allocation to RME was the lowest with the substitution method, resulting in the highest energy ratio. Previous studies showed different results. The energy ratio of RME was 2.99 with the allocation by mass [5] while it ranged from 1.96 to 2.7 with the substitution method [2, 3]. The differences between these results arose from both differences in methods and differences in data. The effect of the data set is illustrated by the difference between the ratio of 2.99 in the Ademe-Direm-Ecobilan [5] study and the ratio of 3.68 in the present study (table 3). The increased ratio resulted from improvements in crop management from 2002 to 2007 and in industrial processes, and from a more realistic estimation of the diesel consumption by farmers in the present study. The three ratios calculated in the present study (table 3) illustrate the effect of the method. However, these results do not mean that the energy ratio is always greater with the substitution method. With this latter method, the amount of energy deducted from the total energy input depends on the possible change of utilizations of the co-products, and on the fluctuation of the energy cost of the products which are replaced.

\section{The method of mass allocation of energy input is better than the substitution method to follow improvements of the energy balance}

Rapeseed methyl ester significantly contributes to the replacement of fossil energy, but percent of the total rapeseed area in France. improvements may be possible. In order to test this possibility, a method of calculation of the energy ratio must be chosen. The substitution method is the best one to evaluate the actual impact of RME [4]. However, this method is not relevant to follow improvements, because with such a method the energy ratio is unstable due to changes of use of the co-products, or due to fluctuations of the energy cost of the products which are replaced. Hence, the allocation by mass or by energy content must be chosen. The former method was used in this study, in order to examine improvements during the 5 past years by comparing the results with those of the previous French study on RME [5].

\section{A great variability in the energy ratio of RME was observed in 2005 and 2006}

Rapeseed is mainly grown in the North-Eastern regions of France (figure 1). The development of this crop in other regions will be necessary in order to meet the target of use of biofuel. Data were collected on individual fields in 2005 (1918 field data in 13 of the 15 French agricultural regions) and in 2006 (829 field data in 7 of the 15 French agricultural regions) in order to calculate the energy ratio. In both years, the

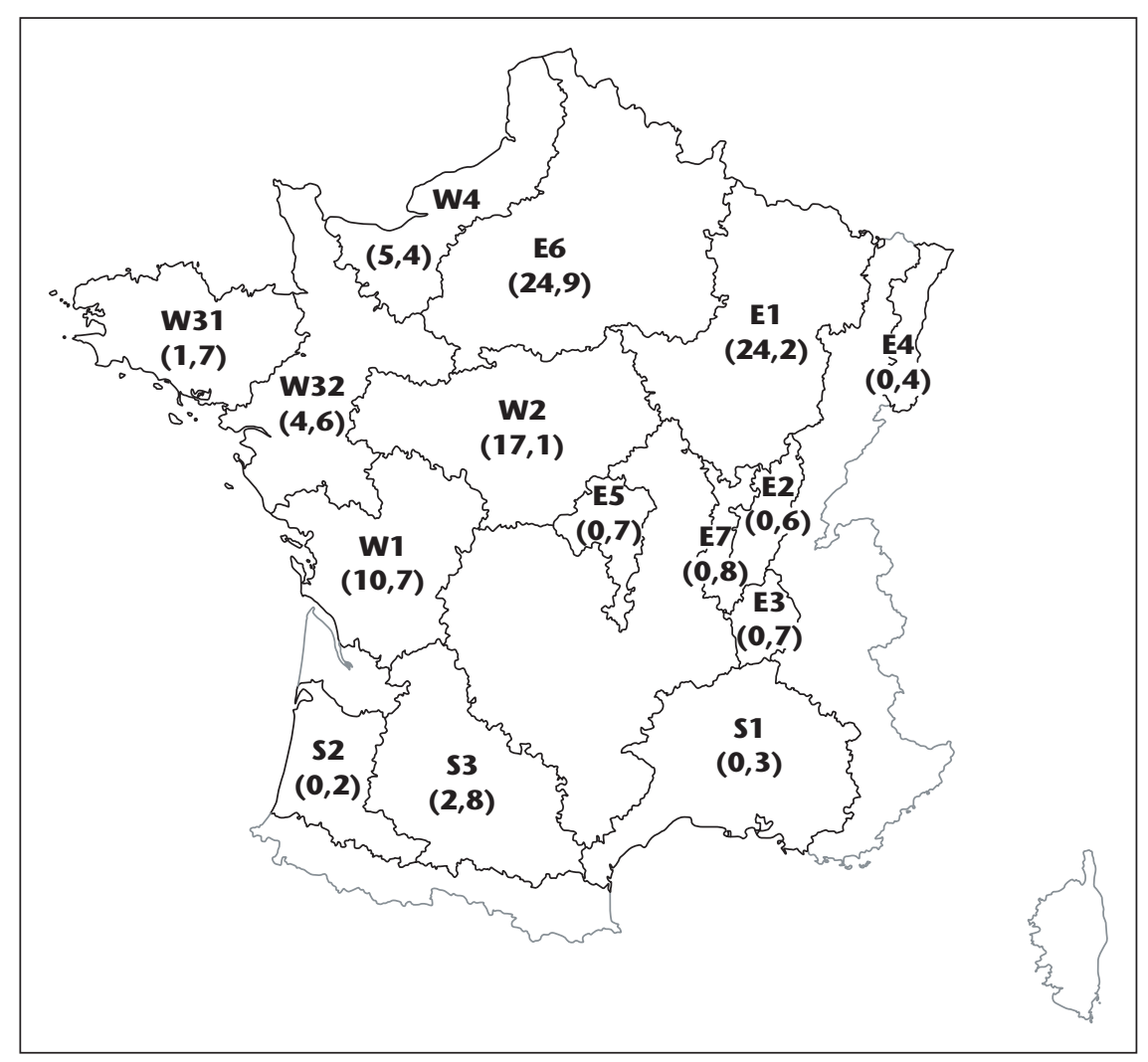

Figure 1. Areas cultivated in rapeseed in the French agricultural regions. E1-7: eastern regions number 1 to 7; W1-4: western regions number 1 to 4; S1-3: southern regions number 1 to 3. In brackets: areas cultivated in rapeseed, in 
mean energy ratio (figure 2) was close to the value of Sofiproteol-Ecobilan [6]. However, a great variability of energy ratios was observed between agricultural regions, and within each region as shown by the standard deviations. Despite this variability, the differences between regions were large enough to conclude that the energy ratios were greater in the cattle breeding areas W31 and W32. On the other hand, energy ratios were lower in the regions where rapeseed is mainly grown (E1, E6, W2 and $\mathrm{W} 1$ ). This variability in energy ratios suggested the possibility of improvements. This was investigated by analyzing values of individual fields.

\section{Seed yields and the energy cost of fertilizer $\mathbf{N}$ explained most of the variability of energy ratios}

Energy ratios of individual fields ranged from 1 to 4.5 in 2005 and from 2 to 4.5 in 2006 (figure 3). In both years, there was a tendency of increased energy ratios with increasing seed yields. This was expected, because for a given energy cost to grow crops, the energy ratio increases with seed yield. However, low and high energy ratios were observed at almost any seed yield, indicating that the energy cost had also a great effect in these data sets. In rapeseed, the energy cost to produce fertilizer $N$ is the greatest. Hence, energy ratios vs. seed yield

A

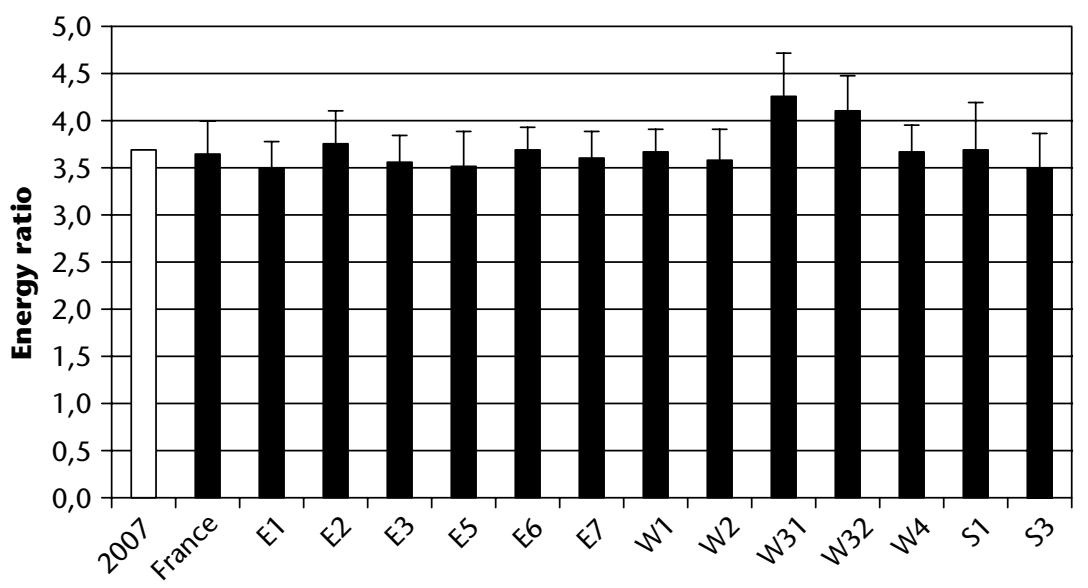

B

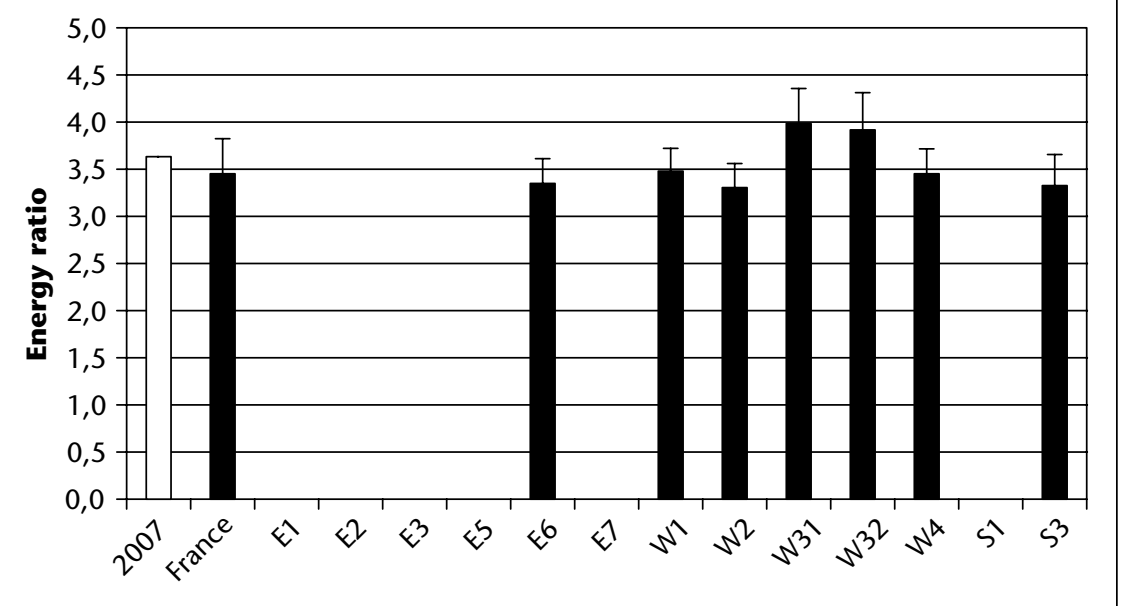

Figure 2. Mean energy ratio in 2005 (A) and 2006 (B). 2007: Sofiproteol - Ecobilan (2007). France: Mean values of the ratios of individual fields in France in 2005 (A) and 2006 (B). E1-7, W1-4 and S1-3: Mean values of the ratios of individual fields in agricultural regions in 2005 (A) and 2006 (B). The error bars are the standard deviations.

were analyzed for given levels of fertilizer $\mathrm{N}$ (figure 4). High positive correlations were observed. In both years, the greater was the level of fertilizer $\mathrm{N}$, the greater was the increase in the energy ratio with seed yield. On the other hand, the greater was the seed yield, the smaller was the increase in the energy ratio with increasing seed yield. The small scattering of values along each correlation was due to the variability of other energy costs. These results indicate that the variability of seed yields and of fertilizer $\mathrm{N}$ explained most of the variability of energy ratios. Hence, the ways of improvement should focus on these two factors. The data presented in figure 4 were observed on fields without application of organic matter. Similar correlations were observed with the application of organic matter (data not shown). However, the mean energy ratio was greater with than without organic matter because, on average, less fertilizer $\mathrm{N}$ was applied. This is the reason why the mean energy ratios were greater in cattle breeding areas.

\section{Improvements of the energy ratio should focus on increasing yield with little increase in energy cost, and on decreasing wasting of fertilizer N...}

An increase in seed yield will increase the energy ratio as long as it is obtained without increasing the energy cost of crop management. For instance, it may arise from a better positioning of pesticides. In rapeseed, numerous insects and fungus can decrease seed yield. Frequent observations are necessary in order to detect these enemies, and to apply pesticides at the right time. There is a need to develop easy tools, or forecasts, to help farmers to protect their crops. On the other hand, the effect of insects and fungus could be limited by integrated pest management.

In order to increase seed yield, it may also be necessary to increase the application of inputs, and thus to increase the energy cost. In such cases, the effect on the energy ratio will depend on the balance between the increase in seed yield and the increase in energy cost. The threshold above which the energy ratio will decline depends on its initial value (figure 5). The greater is the initial energy ratio, the lower is the threshold value. This means that it will be more difficult to improve high values of energy ratio. For most initial values, the threshold is high enough to obtain an improvement if the increased input is profitable, except for $\mathrm{N}$ fertilizer which is too costly in energy. The average increase in rapeseed yield with increasing $N$ fertilizer, observed in experiments, is presented 


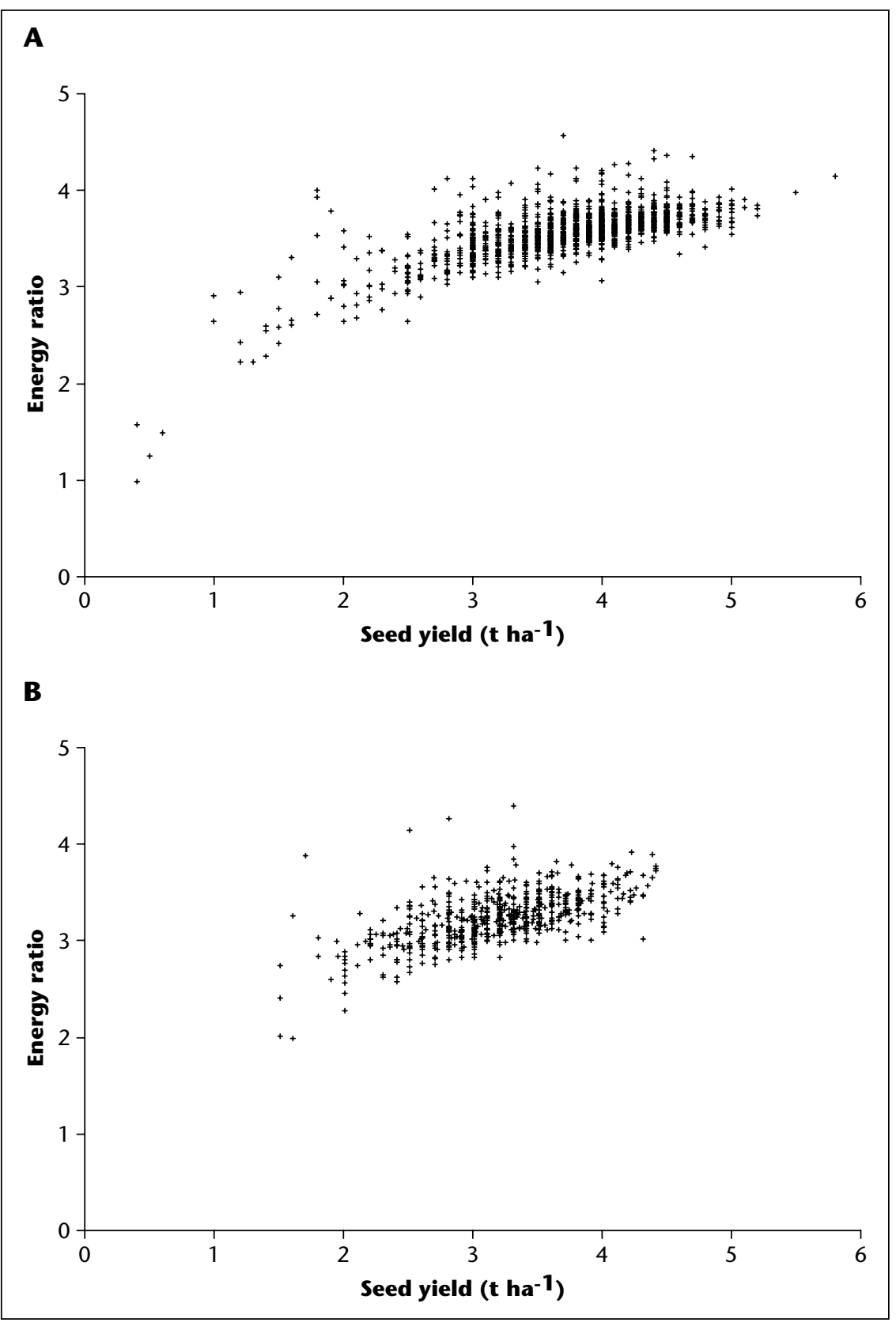

Figure 3. Energy ratios of individual fields in 2005 (A) and 2006 (B) vs seed yields. Data presented in this figure where obtained on fields cultivated without application of organic matter.

in figure 6. The increase in seed yield per unit of $\mathrm{N}$ declined as the total amount of fertilizer was getting close to the optimal value, which was the minimum to obtain the maximum yield (no statistical difference at the $5 \%$ level). Hence, the energy cost of an increase in yield increased with the total amount of $\mathrm{N}$ fertilizer. The minimum energy cost, observed in plants with high $\mathrm{N}$ deficiency, was about $5000 \mathrm{MJ} \mathrm{t}^{-1}$ (figure 6) which is the maximum value for an increase in the energy ratio when its initial value is about 3.0 (figure 5). However, energy ratios of rapeseed crops with little or no $\mathrm{N}$ fertilizer are accurate calculation of the amount of $\mathrm{N}$ fertilizer, by taking into account the $\mathrm{N}$ uptaken by plants during autumn and winter. In France, for most winter crops the amount of $\mathrm{N}$ fertilizer needed to meet plant requirement is calculated at the end of winter by taking into account mineral soil $\mathrm{N}$ available for plants at this time and the expected soil $\mathrm{N}$ mineralization. The $\mathrm{N}$ already uptaken by plants is small. Thus, there is no need to take it into account. Winter rapeseed is different from other winter crops because it can uptake a large amount of $\mathrm{N}$ during autumn and winter. Hence, this $\mathrm{N}$ already uptaken, which contributes to the plant requirement, must be taken into account in the calculation of the amount of $\mathrm{N}$ fertilizer. Further improvements are possible because half of farmers take into account only a rough estimate (visual appreciation) of $\mathrm{N}$ uptaken during autumn and winter. The development of more accurate estimations, by weighing plants or by using remote sensing, would make possible such improvements. More accurate estimations of soil $\mathrm{N}$ mineralization and of $\mathrm{N}$ requirement of plants would also improve the calculation of the amount of $\mathrm{N}$ fertilizer. It would either decrease the amount of $\mathrm{N}$ fertilizer or increase seed yield. Such improvements are under investigation.

An improvement in the efficiency of $\mathrm{N}$ fertilizer, calculated as the ratio between the increased $\mathrm{N}$ uptake due to the application of the fertilizer and the amount applied, would also decrease the energy cost of rapeseed crop management. In wheat, Limaux [8] observed improved efficiencies of $\mathrm{N}$ fertilizer when it was applied during the period of rapid growth of plants. In rapeseed, the applications of $\mathrm{N}$ fertilizer in autumn are less efficient than the applications from the end of winter to spring (unpublished data). This is consistent with Limaux observations, because growth of rapeseed plants is slow during autumn. Applications of $\mathrm{N}$ fertilizer during this period of time has dramatically decreased from 16\% to 3\% (Unpublished data). However there is still a great variability in the efficiencies of $\mathrm{N}$ fertilizer, which range from 0.2 to 1.0 (unpublished data). Further improvements in the timing of $\mathrm{N}$ fertilizer application are probably needed.

Application of organic matter is also a way to decrease the amount of synthetic $\mathrm{N}$ fertilizer, and hence to decrease the energy cost. Organic matter which is often in excess in cattle breeding farms could be applied in the fields of other farms. Other sources of organic matter are also available, like carcass meal from BSE free animals other than bovines. The possibility to apply large amount of organic matter before sowing winter rapeseed, without increasing nitrate leaching during winter, is under investigation. The ability to calculate 


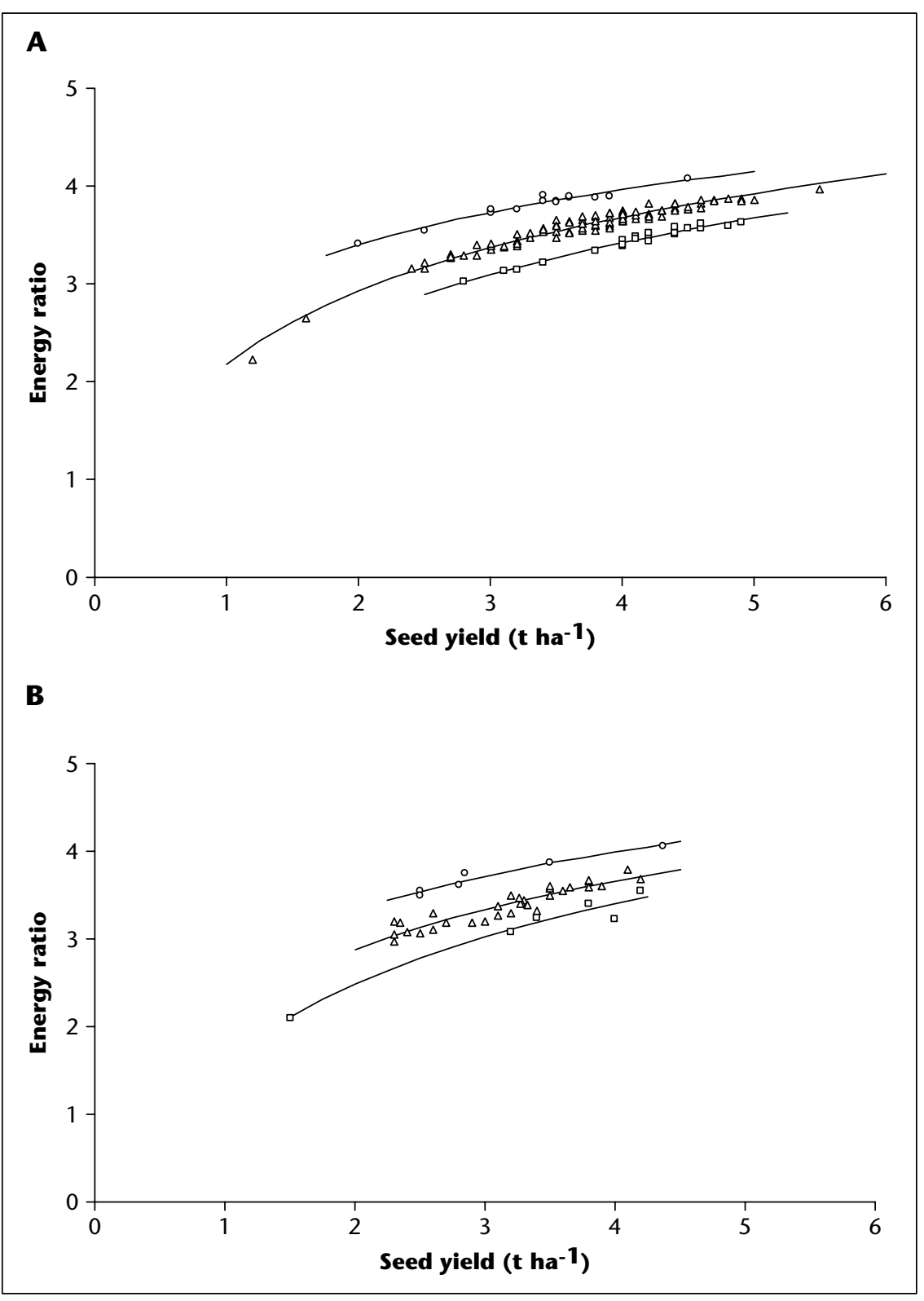

Figure 4. Energy ratios $\left(E_{r}\right)$ of individual fields in 2005 (A) and 2006 (B) vs seed yields $\left(Y_{s}\right)$, for three levels of fertilizer nitrogen. The three levels of fertilizer nitrogen were selected to illustrate the effect on the energy ratio: 100-104 $(\odot)$, 160-164 (4) and 220-224 (口) $\mathrm{kg} \mathrm{N} \mathrm{ha}^{-1}$.

$2005(A) / 100-104 \mathrm{~kg} \mathrm{Nha}^{-1}: E_{r}=1.87 \mathrm{LOG}\left(Y_{s}\right)+2.84 ; R^{2}=0.96 / 160-164 \mathrm{~kg} \mathrm{Nha}^{-1}: E_{r}=2.50 \mathrm{LOG}\left(Y_{s}\right)+2.18 ;$ $R^{2}=0.96 / 220-224 \mathrm{~kg} \mathrm{Nha} a^{-1}: E_{r}=2.61 \operatorname{LOG}\left(Y_{s}\right)+1.85 ; R^{2}=0.97$

$2006(B) / 100-104 \mathrm{~kg} \mathrm{Nha}{ }^{-1}: E_{r}=2.23 \mathrm{LOG}\left(Y_{s}\right)+2.65 ; R^{2}=0.96 / 160-164 \mathrm{~kg} \mathrm{Nha}^{-1}: E_{r}=2.60 \mathrm{LOG}\left(Y_{s}\right)+2.09$. $R^{2}=0.87 / 220-224 \mathrm{~kg} \mathrm{Nha}^{-1}: E_{\mathrm{r}}=3.05 \operatorname{LOG}\left(Y_{s}\right)+1.57 ; R^{2}=0.97$.

accurately the amount of synthetic $\mathrm{N}$ fertilizer in this case is also checked.

\section{... but the farmer income, and the net production of energy per hectare, must also be a matter of concern}

The improvement of the energy ratio, based on both decreased energy cost and seed yield,

\section{In order to assess the effect of rapeseed on greenhouse gas emissions, accurate methods of evaluation are still under investigation}

The $\mathrm{CO}_{2}$ emitted when using rapeseed oil as biofuel comes from the atmosphere. Hence, there is no net emission of $\mathrm{CO}_{2}$, while this is the contrary with fossil fuels. However, rapeseed oil is not used directly, but after esterification with methanol which comes from a fossil resource. Moreover, some greenhouse gases are emitted during the production of biodiesel, because of industrial processes (to produce agricultural inputs, and to process the seeds), transports and emissions by soils. These emissions must be taken into account when comparing the global effects of biodiesel and fossil fuels, as well as the $\mathrm{CO}_{2}$ emitted by methanol. The calculations of these emissions are rather accurate for industrial processes, transports and methanol while there are great uncertainties for emissions by soils, especially for $\mathrm{N}_{2} \mathrm{O}$. This greenhouse gas is emitted under anaerobic conditions during the sequential reactions of denitrification which produce $\mathrm{N}_{2} \mathrm{O}$ and $\mathrm{N}_{2}$ from $\mathrm{NO}_{3}{ }^{-}$[9]. Emission of $\mathrm{N}_{2} \mathrm{O}$ can also result from nitrification. An increase in available $\mathrm{N}$ enhances nitrification and denitrification rates, and then increases $\mathrm{N}_{2} \mathrm{O}$ emission which is linearly correlated with the amount of $\mathrm{N}$ application as fertilizer or organic matter [10]. Hence, the International Panel on Climate Change suggests a methodology of calculation using an emission factor which is the percentage of $\mathrm{N}$ application which is emitted [11]. This emission factor is $1 \%$ with an uncertainty range of $0.3 \%$ to $3 \%$. Such a large uncertainty is due to factors affecting $\mathrm{N}_{2} \mathrm{O}$ emissions, which are biological soil parameters, soil water-filled pore space and temperature [12]. The use of such an emission factor for a given field is inaccurate and cannot allow the test of different management scenarios such as no-till, cover crop or change in $\mathrm{N}$ fertilizer timing. Process oriented models which account for management practices can be used, instead of emission factors. The Denitrification-Decomposition (DNDC) model [13] and the Nitrous Oxide Emission (NOE) model [12] have been tested in European conditions with promising results $[12$, 14]. However, while the seasonal simulated values agree rather well with measurements, there are many discrepancies in daily emissions. Moreover, these models must be tested in all conditions of expected use (environment and management factors such as till or no till...). Hence, further comparisons between simulations and field measurements are needed before using these models for confident $\mathrm{N}_{2} \mathrm{O}$ emission inventories or management scenarios testing. 

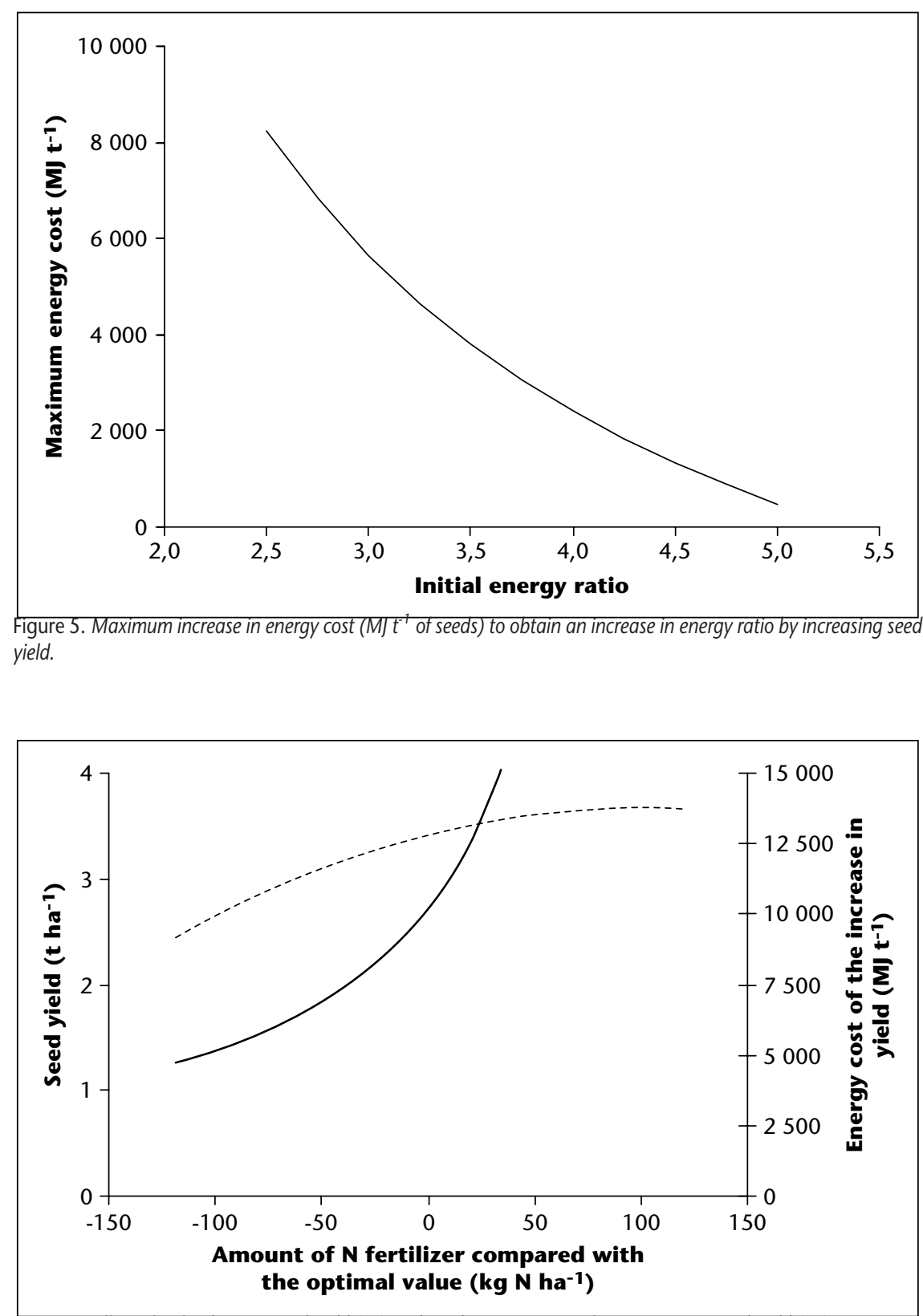

Figure 6. Effect of $N$ tertilizer on seed yield (- -) and on the energy cost of an increase in seed yield (-).

Seed yield is the correlation of experimental values vs fertilizer N (73 Experiments from 1993 to 1999; [15]).

Indirect emissions from addition of $\mathrm{N}$ to natural land, due to both $\mathrm{NH}_{3}$ volatilized and $\mathrm{NO}_{3}{ }^{-}$ leached from fields, must also be taken into account. There are also great uncertainties in estimating volatilization and leaching (respectively from 3 to $50 \%$ and from 10 to $80 \%$ of $\mathrm{N}$ input), and their emission factors (respectively from 0.2 to $5 \%$ of $\mathrm{N}$ volatilized and from 0.05 to $2.5 \%$ of $\mathrm{N}$ leached) [11].

Overall, global inventories at the world level as done by Crutzen et al. [1] are not relevant to evaluate rapeseed biodiesel production in a given area, due the uncertainties in both direct and indirect emissions resulting from the variability between areas. Moreover, such global

\section{REFERENCES}

1. CRUTZEN P], MOSIER AR, SMITH KA, WINIWARTER W. $\mathrm{N}_{2} \mathrm{O}$ release from agro-biofuel production negates global warming reduction by replacing fossil fuels. Atmos Chem Phys Discuss 2007; 7: 11191-205.

2. ADEME-ECOBILAN. Bilan énergétique et émissions de GES des carburants et biocarburants conventionnels. Convergences et divergences entre les principales études reconnues (citées). Rapport technique. 2006.

3. SOURIE JC, TRECUER D, ROZAKIS S L'ambivalence des filières biocarburants. Publication du Département Sciences Sociales, Agriculture et Alimentation, Espace et Environnement de l'INRA, ${ }^{\circ} 2,20^{\mathrm{e}}$ année, 2005.

4. ISO. Management environnemental. Analyse du cycle de vie. Définition de l'objectif et du champ d'étude et analyse de l'inventaire, NF EN ISO 14041. Afnor, 1998.

5. ADEME-DIREM-ECOBILAN. Bilans énergétiques et gaz à effet de serre des filières de production de biocarburants. Rapport technique. 2002.

6. SOFIPROTEOL-ECOBILAN. Actualisation du bilan énergétique et du bilan gaz à effet de serre de I'EMHV en France. Rapport technique. 2007.

7. REAU R. Bilan énergétique et gaz à effet de serre: perspectives agricoles. OCL 2006; 13 : 117-20.

8. LIMAUX F. Modélisation des besoins du blé en azote, de la fourniture du sol et de l'utilisation de l'engrais. Application au raisonnement de la fertilisation en Lorraine. Thèse de doctorat. Institut National Polytechnique de Lorraine, Nancy, 1999.

9. LIC. Quantifying greenhouse gas emissions from soils: scientific basis and modeling approach. Soil Sci Plant Nutr 2007; 53: 344-52.

10. BOUWMANEG. Direct emission of nitrous oxide from agricultural soils. Nutr Cycl Agroecosyst 1996; 46: 53-70.

11. IPCC. Guidelines for National Greenhouse Gas Inventories. 2006.

12. HENAULT C, BiZOUARD F, LAVILLE P, ET AL. Predicting in situ soil $\mathrm{N}_{2} \mathrm{O}$ emission using $\mathrm{NOE}$ algorithm and soil database. Glob Change Biol 2005; 11: 115-27.

13. LI C, FROLKING S, FROLKING T. A model of nitrous oxide evolution from soil driven by rainfall events: 1. Model structure and sensitivity. / Geophys Res 1992; 97: 9759-76. processed-oriented models. The objective is to be able to calculate accurate inventories and to test management scenarios. When this objective is achieved, an accurate evaluation of rapeseed biodiesel on both energy balance and greenhouse gas emission will be possible, allowing the demonstration and the improvement of the interest of this biofuel.

Acknowledgements. The authors wish to thank Sofiproteol for financial support, and for discussion about the results.
14. NEUFELDT H, SCHÄFER M, ANGENENDT E, LI C, KALTSCHMITT M, ZEDDIES J. Disaggregated greenhouse gas emission inventories from agriculture via a coupled economicecosystem model. Agr Ecosyst Env 2006; 112: 233-40.

15. CACERES F. Comment gérer au mieux la fertilisation azotée du colza? In: Brochure colza. CETIOM, 2006. 